\title{
Linear Algebra Continuous Dynamic Control for WMR
}

\author{
Sebastian A*, Mario E Serrano, Francisco G Rossomando and Gustavo J E Scaglia \\ Universidad Nacional de San Juan, Argentina
}

Submission: July 13, 2017; Published: September 07, 2017

*Corresponding author: Sebastian Godoy, Universidad Nacional de San Juan, Av. Lib. San MartÃ $n$ (Oeste) 1109, Argentina, Tel: 542644211700;

Email: sgodoy@unsj.edu.ar

Abstract

A trajectory tracking controller for wheeled mobile robot (WMR) is presented in this paper. The approach is based on the dynamic model of a nonholonomic mobile robot. The non linear dynamic model is used to find the expression of the control actions which make the robot follow a desired trajectory. The methodology for controller design is based in Linear Algebra theory. Experimental results in a Pioneer 3DX mobile robot are presented and compared with other approach of the literature.

Keywords: Index terms-non-linear system, Mobile robot, Tracking trajectory, Linear algebra.

\section{Introduction}

For many years, the trajectory tracking problem in mobile robots has been addressed by the research community [1-5]. One of the reasons is that the tracking control approach results more appropriate, since the nonholonomic constraints and other control tasks (obstacle avoidance, minimum travel time, minimum fuel consumption) are implicitly included in the path-planning procedure.

This paper presents a novel methodology to deal with the problem of trajectory tracking in WMR. This new approach uses the dynamic model of WMR and allows perfect velocities tracking. Generally, the classic control approaches applied to the dynamic model of the robot solve the problem of trajectory tracking in two stages. In the first one is designed a controller that ensures the perfect tracking of the velocities considering only the kinetic structure of the model. The second stage solves the problem of tracking velocities using the dynamics of the system $[1,2]$. In our work, the procedure arises naturally when looking for the conditions that a system must meet in order to have an exact solution. The control action is obtained by solving a linear system, even though the original system model is nonlinear. Compared with other literature methods (back stepping, look-ahead methods, finite-time techniques, etc.), only algebra knowledge is needed to understand and apply this methodology. The controller performance is evaluated and compared with other controllers of the literature through laboratory experiments in PIONEER 3DX mobile robot.
The paper is ordered as follows. In Section 2 are described the mathematical model of the mobile robot and the control design of the proposed controller. Section 3 presents the experimental results using a mobile robot Pionner 3DX. Finally, Conclusions are detailed in Section 4.

\section{Dynamic Model-Control Design}

In this section is described the dynamic model used (1). It model has been used in several works of the literature $[1,2]$. This model allows that the linear and angular reference velocities are now considered as the input signals. These signals are usual inputs in commercial robots. The dynamic model of the mobile robot is given by:

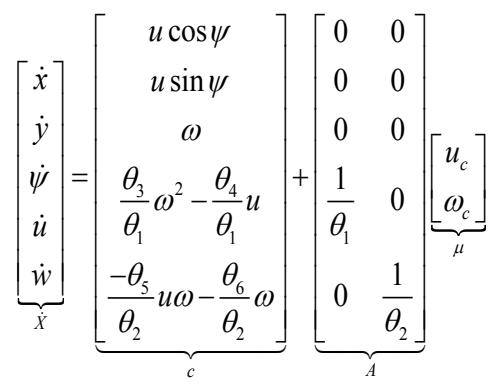

Where $\mathrm{u}_{c}$ and $\omega_{c}$ are the control action of the system, its represent the linear and angular velocity commands given to the robot. The variables $\dot{x}, \dot{y}, \dot{\psi}, \dot{u}, \dot{\omega}$ represent the variations of the horizontal and vertical position, orientation and linear and angular velocities respectively. The identified parameters 


\section{Robotics \& Automation Engineering Journal}

$\theta=\left[\theta_{1}, \theta_{2}, \theta_{3}, \theta_{4}, \theta_{5}, \theta_{6}\right]^{T}$ of the dynamic model are functions of the physical parameters of the robot.

The aims is to find the values of the $\mathrm{u}_{c}$ and $\omega_{c}$ such that the mobile robot follow a predefined reference trajectory $\left(x_{d}, y_{d}\right)$ with minimal error, for that is proposed a control law based on the parameterized dynamic equation of the model (1). Then a Proportional replacement $\dot{X}=\dot{X}_{d}+K e$ is proposed, where, $\dot{X}_{d}=\left[\dot{x}_{d}, \dot{y}_{d}, \dot{\psi}_{d}, \dot{u}_{d}, \dot{\omega}_{d}\right]^{T}, K=\left[k_{x}, k_{y}, k_{\psi}, k_{u}, k_{\omega}\right]^{T}$.The variables in $\dot{X}_{d}$ are the derivatives functions of the desired trajectory to be followed, the elements of are constants greater than zero and represents the controller parameters, where $k_{\psi}<k_{\omega}$, and $\mathrm{e}_{x}, \mathrm{e}_{y}, \mathrm{e}_{\psi}, \mathrm{e}_{u}, \mathrm{e}_{w}$ are the state variable tracking errors.

Remark 1. The tracking error is represented by

$$
\|e\|=\sqrt{\left(e_{x}^{2}+e_{y}^{2}+e_{\Psi}{ }^{2}+e_{u}{ }^{2}+e_{\omega}^{2}\right)}
$$

Where $\mathrm{e}_{x}=\mathrm{x}_{d}-\mathrm{x}, \mathrm{e}_{y}=\mathrm{y}_{d}-\mathrm{y}, \mathrm{e}_{\psi}=\psi_{d}-\psi, \mathrm{e}_{u}=\mathrm{u}_{d}-\mathrm{u}$ and $\mathrm{e}_{\omega}=\omega_{d}-\omega$ Then, the system (1) can be rearranged in:

$$
A \mu=\dot{X}_{d}+K e-C=b
$$

The expression (2) represents a system of linear equation of the form $\mathrm{A}_{\mu}=\mathrm{b}$. This system has five equations with two unknown variables and can be solved through least square theory $\mathbf{A}^{T} \mathbf{A}_{\mu}=\mathbf{A}^{T} \mathbf{b}$ [6] then, the proposed controll. $\mu=\left[\begin{array}{l}u_{c} \\ \omega_{c}\end{array}\right]=\left[\begin{array}{c}\theta_{1}\left(\dot{u}_{d}+k_{u} e_{u}\right)-\theta_{3} \omega^{2}+\theta_{4} u \\ \theta_{2}\left(\dot{\omega}_{d}+k_{\omega} e_{\omega}\right)+\theta_{5} u \omega+\theta_{6} \omega\end{array}\right]$

Equation (3) represents the optimal control actions should be applied to follow the desired trajectories with minimal error. Now, (2) should have an exact solution, its mean that the vector $b$ must belong to column space of the matrix A, [6]. Analyzing the system (2) is observed that the first three equation of the vector $b$ must be equal to zero in order to the system has an exact solution. It is

$$
\underbrace{\left[\begin{array}{cc}
\cos \psi & 0 \\
\sin \psi & 0 \\
0 & 1
\end{array}\right]}_{B} \underbrace{\left[\begin{array}{c}
u \\
\omega
\end{array}\right]}_{v}=\underbrace{\left[\begin{array}{c}
\dot{x}_{d}+k_{x} e_{x} \\
\dot{y}_{d}+k_{y} e_{y} \\
\dot{\psi}_{d}+k_{\psi} e_{\psi}
\end{array}\right]}
$$

Now, analyzing (4) is observed that is composed by three equation with two unknown variables, where is resolved using normal equations $\left(B^{T} B v=B^{T} c\right)$ and then the optimal solution (using least squares [6]) can be found such as $v=\mathrm{B}^{T} \mathrm{c}$. The optimal solution obtained represents the linear and angular velocities that the mobile robot must have so that system (2) has an exact solution.

The value of $\psi_{d}$ is found forcing the vector $\mathrm{c}$ to belong in

The column space of $B$, [6] and his expression is tan $\psi_{d}=\frac{\sin \psi_{d}}{\cos \psi_{d}}=\frac{\dot{y}_{d}+k_{y} e_{y}}{\dot{x}_{d}+k_{x} e_{x}}$. The desired orientation $\psi_{d}$ represents the necêssary guidance for that the system (4) has an exact solution. The proposed controller design is completely finished by using the derivate of the relations given in (5), which will be used to generate the control signals in (3).

\section{Experimental Results}

The experiment was performed using a PIONEER 3DX mobile robot. The controller developed (C1) has been compared with two developments, C2: presented in Scaglia et al. [4] and C3: presented Cassius et al. [3]. C1 was adjusted with $k_{x} ; k_{y} ; k_{\psi} ; k_{u} ; k_{\omega}=[1: 1 ; 1.07 ; 0.92 ; 1.98 ; 2.06]$. C2 and C3 were implemented in the same PIONEER 3DX. For three controller the performance was evaluated using the cost functions defined in (6) for each experiment realized. Let ${ }^{\phi}$ be a desired trajectory, where $t_{f}$ is the final time of the desired trajectory. Thus, the cost function can be represented by

$$
C^{\phi}=\frac{1}{2}\left(\int_{0}^{t_{f}}\left(x_{d}(t)-x(t)\right)^{2} d t+\int_{0}^{t_{f}}\left(y_{d}(t)-y(t)\right)^{2} d t\right)
$$

The experimentation is a test recommended in Roth \& Batavia [7] and is formed by three different circle-shaped. The reference trajectory and the results of each controller are shown in Figure 1. As can be seen, all controllers reach and follow the desired trajectory. Figure 2 show the tracking error in the $x$-coordinate and $y$-coordinate for each controller. The errors for all controllers remains bounded and close to zero when the robot reaches the reference trajectory. The tracking cost calculated for each controller according to (6) is: $\mathrm{C} 1=0.92$; $\mathrm{C} 2=1.41 ; \mathrm{C} 3=4.19$. As can bee seen, the proposed algorithm C1 present the lowest value.

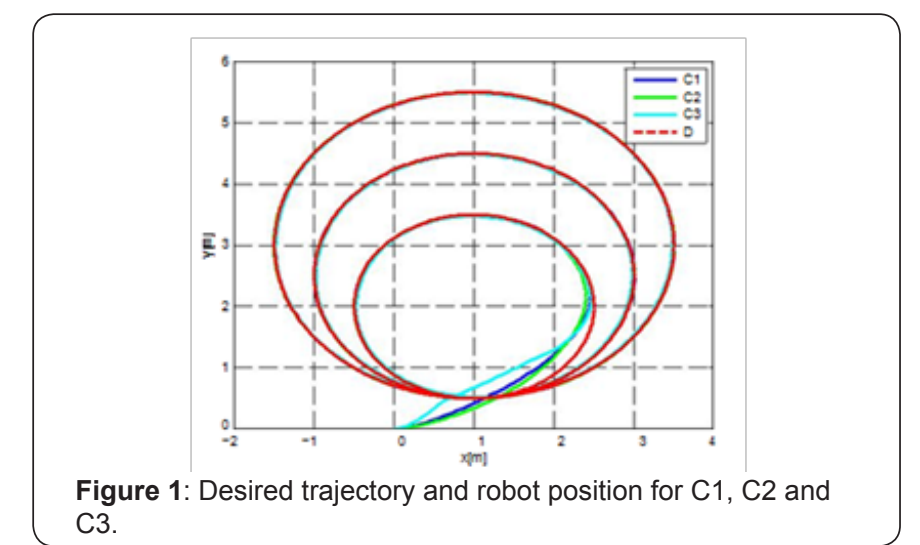
C3.

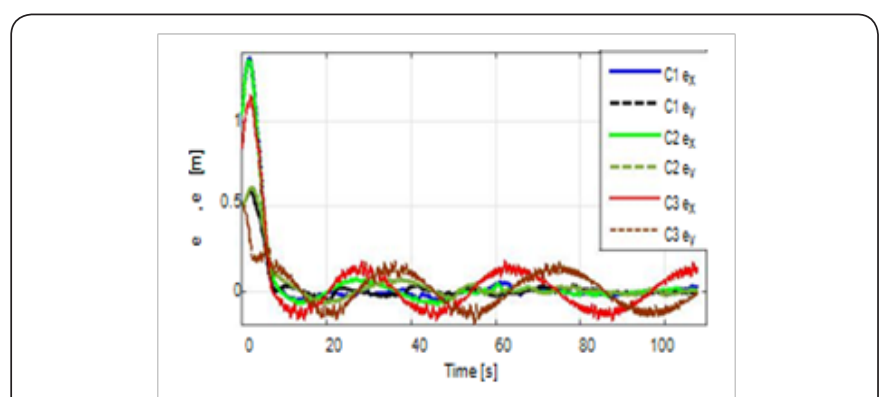

Figure 2: Tracking error in $\mathrm{x}(\mathrm{ex})$ and $\mathrm{y}\left(\mathrm{e}_{\mathrm{y}}\right)$ for each controller

\section{Conclusion}

A methodology based on numerical methods and linear algebra to controller design for mobile robot taking into account the non linear multivariable dynamic model has been presented. The methodology finds the control expressions that 


\section{Robotics \& Automation Engineering Journal}

minimize the tracking errors using algebraic techniques without requiring the linearization of the dynamic model. Thus, the controller is independent of the operating point. In addition, as the controller structure comes from the mathematical model of the system it can be implemented in much other system. The experimental test shows the good perfor mance of the proposed controller.

\section{References}

1. Celso DLC, Ricardo C (2008) Dynamic model based forma-tion control and obstacle avoidance of multi-robot systems. Robotica 26(3): 345356

2. Felipe NM, Wanderley CC, Ricardo C, Sarcinelli-Filho M, Bastos-Filho TF (2008) An adaptive dynamic controller for autonomous mobile robot trajectory tracking. Control Engineering Practice 16(11): 1354-1363.
3. Resende CZ, Ricardo C, Sarcinelli-Filho M (2013) A nonlinear trajectory tracking controller for mobile robots with velocity limitation via fuzzy gains. Control Engineering Practice 21(10): 1302-1309.

4. Roth SA, Batavia P (2002) Evaluating path tracker performance for outdoor mobile robots.

5. Gustavo S, Luc'ia QM, Vicente M, di Sciascio F (2009) Numerical methods based controller design for mobile robots. Robotica 27(2): 269-279.

6. Mario ES, Godoy AS, Vicente AM, Oscar AO, Gustavo JES (2015) A nonlinear trajectory tracking controller for mobile robots with velocity limitation via parameters regulation.

7. Gilbert S (2006) Linear Algebra and Its applications. (4 $4^{\text {th }}$ edn), Brooks/ Cole, USA, p. 544

\section{Your next submission with Juniper Publishers} will reach you the below assets

- Quality Editorial service

- Swift Peer Review

- Reprints availability

- E-prints Service

- Manuscript Podcast for convenient understanding

- Global attainment for your research

- Manuscript accessibility in different formats

( Pdf, E-pub, Full Text, Audio)

- Unceasing customer service

Track the below URL for one-step submission https://juniperpublishers.com/online-submission.php 